\title{
LA RESPONSABILIDAD CIVIL EXTRACONTRACTUAL DE LOS NIÑOS Y ADOLESCENTES
}

\author{
THE EXTRACONTRACTUAL CIVIL LIABILITY OF CHILDREN \\ AND ADOLESCENTS
}

\author{
Ocner Córdova López* \\ Investigador independiente \\ Lima-Perú \\ https:/ /orcid.org/0000-000-3242-0811 \\ ocner75@hotmail.com
}

\section{Resumen}

Los niños y adolescentes cuando actúan con discernimiento son responsables civilmente por los daños que pudieran causar; sin embargo, cuando el daño es causado por un niño que no tiene capacidad de discernimiento no se le puede imputar ninguna responsabilidad, puesto que, no ha tenido la capacidad de comprender ni querer el acto que ha ocasionado daño. Sin embargo, la víctima no puede quedar sin resarcimiento por el daño injusto sufrido, es muy probable que los niños y adolescentes no cuenten con un patrimonio con el que puedan contar para el resarcimiento; en este caso, a efectos de que la víctima no quede afectada injustamente algunos códigos civiles han previsto que en estos casos deben responder los padres o los representantes legales del menor. Nuestro Código Civil, si bien en su artículo $458^{\circ}$ ha regulado la responsabilidad civil del menor capaz de discernimiento, sin embargo, después de la derogación de los artículos $1975^{\circ}$ y $1976^{\circ}$ omite regular respecto de la responsabilidad civil de los padres por los hechos dañosos de sus hijos menores.

Palabras Clave: responsabilidad civil, niños y adolescentes, responsabilidad de los padres, capacidad de discernimiento.

\section{Abstract}

When children and adolescents act with discernment, they are civilly responsible for the damages they may cause; however, when the harm is caused by a child who does not have the ability to discern, no responsibility can be attributed to him, since he

Magistrado de la Corte Superior de Justicia de Lima Este -Poder Judicial del Perú. Magister en Derecho Civil, Juez Titular del Segundo Juzgado Civil de San Juan de Lurigancho. 
has not had the ability to understand or love the act that has caused harm. However, the victim can not be without compensation for the unjust damage suffered, it is very likely that children and adolescents do not have a heritage that they can count on for compensation; In this case, in order that the victim is not unfairly affected, some civil codes have provided that in these cases the parents or legal representatives of the minor must respond. Our Civil Code, although in its article $458^{\circ}$ has regulated the civil responsibility of the minor capable of discernment, however, after the repeal of articles $1975^{\circ}$ and $1976^{\circ}$ omits to regulate regarding the civil responsibility of parents for the facts harmful of their minor children.

Keywords: Civil responsibility, children and adolescents, parental responsibility, capacity for discernment.

\section{INTRODUCCIÓN}

Una de las funciones principales de la responsabilidad civil es el resarcimiento del daño causado, es decir se busca resarcir a la víctima por el daño sufrido. Es un principio de la responsabilidad civil que quien ha causado un daño injusto (como lo dice el código civil italiano) responda con su patrimonio. Sin embargo, para que se pueda responder por el daño causado es preciso y necesario que quien haya causa el daño haya actuado con discernimiento, esto es con conciencia de voluntad, con capacidad de entender y comprender. Cuando el daño es ocasionado por un niño o adolescente, este puede ser responsable civilmente y puede quedar obligado a responder por el daño, siempre que haya actuado con discernimiento, así lo dispone el artículo $458^{\circ}$ de nuestro Código Civil. No es la edad el parámetro para establecer si un niño o adolescente es o no responsable civilmente de sus actos, sino la capacidad de discernimiento que este posea; no existe una edad específica para determinar si el niño ha alcanzado o no el discernimiento, sino que será el Juez quien determine caso por caso si el niño o adolescente tiene o no discernimiento. Si bien es cierto que algunos Códigos Civiles establecen una edad para presumir responsabilidad civil en el niño o adolescente, como por ejemplo el Código Civil Alemán que establece presunción de discernimiento después de que el niño ha cumplido siete años de edad o el Código Civil argentino que establece que antes de los diez años no se puede establecer ninguna responsabilidad en el menor; sin embargo, son muy pocos los códigos que se atreven a establecer una edad para presumir capacidad de discernimiento. En realidad, no compartimos la idea de que exista una edad como parámetro para determinar existencia de capacidad de discernimiento, sino que esta debe ser determinada por 
el juez atendiendo al caso particular y concreto, todos sabemos que la capacidad de desarrollo intelectual y comprensión en cada niño no son igual en todos y dependerá de muchos factores.

Cuando la víctima ha sufrido un daño injusto como consecuencia de la actuación de un niño o adolescente, tiene derecho a ser resarcida por ese daño, ello con prescindencia si el niño o adolescente actuó o no con discernimiento; pues, existe un daño causado y este debe ser resarcido por el causante. Si embargo, hay que diferenciar necesariamente si el menor actuó o no con discernimiento, por cuanto si el menor actuó sin discernimiento no puede ser responsable por ese daño porque no estuvo en la capacidad de comprender el hecho causado ni las consecuencias del mismo; distinto es el caso del niño y adolescente que sí actuó con discernimiento, en él sí existe responsabilidad y se encuentra obligado a resarcir el daño causado. Pero, no olvidemos que estamos frente a un daño causado por un niño o adolescente, que, es muy probable que no posea un patrimonio o bienes con qué responder ¿quién responderá en este caso? Al respecto, los Códigos Civiles europeos, francés, español e italiano y algunos Códigos Civiles sudamericanos como el argentino hacen responsable de forma expresa a los padres del menor o a la persona o institución que lo tenía a su cargo al menor, como por ejemplo a la institución educativa. El fundamentos para atribuir la responsabilidad civil a los padres del menor se ha regulado en los códigos civiles europeos de manera subjetiva o cuasi objetiva y en Argentina de manera objetiva; en dichos códigos civiles se parte de la culpa presunta, atribuyen responsabilidad a los padres por la falta de vigilancia y cuidado hacia el menor, existiendo una posibilidad de exonerarse de esta responsabilidad solo si probasen que pusieron toda la diligencia posible y que extremaron los cuidados y vigilancia; sin embargo, la jurisprudencia más actualizada trata de "objetivar esta culpa" con la finalidad de obtener siempre un resarcimiento a favor de la víctima, por cuanto en la práctica es casi imposible que los padres se puedan exonerar de responsabilidad. En nuestro Código Civil, después de la derogación de los artículos $1975^{\circ}$ y $1976^{\circ}$ no se ha regulado la responsabilidad civil que pudieran tener los padres como consecuencia de los daños que pudieran ocasionar sus hijos menores con o sin discernimiento.

\section{I. ¿PUEDEN LOS NIÑOS Y ADOLESCENTES SER RESPONSABLES EXTRACONTRACTUALMENTE ANTE UN DAÑO PRODUCIDO CONTRA TERCEROS?}


En principio, todo aquél que causa un daño a otro, por dolo o por culpa, está obligado al resarcimiento. Sin embargo, para el caso de un niño o adolescente este será responsable directamente solo si tiene discernimiento, esto es si tiene la posibilidad de entender, comprender y razonar sobre los hechos que realiza; la edad no es un parámetro válido para determinar si hay o no responsabilidad civil por el daño causado, sino su capacidad de discernimiento. Hoy en día la capacidad de los niños y adolescentes se desenvuelve bajo el parámetro de progresividad y evolución de facultades, no en base a la edad.

Conforme a la Convención sobre los Derechos del Niño, se define como niño: "Todo ser humano menor de 18 años de edad, salvo que en virtud de la ley que le sea aplicable, haya alcanzado antes la mayoría de edad". Por su parte nuestro Código de los Niños y Adolescentes establece que: "Se considera niño a todo ser humano desde su concepción hasta cumplir los doce años de edad y adolescente desde los doce hasta cumplir los dieciocho años de edad" (Art. I del Título Preliminar).

Debemos partir de la premisa que no todos los niños y / o adolescente que causan un daño a un tercero poseen discernimiento; por tanto, debemos diferenciar entre los niños que tienen discernimiento y los niños que no lo tienen. Pues, solo los niños que tienen discernimiento al momento de la comisión del hecho dañoso, podrían ser responsable extracontractualmente en forma directa y obligados a resarcir el daño.

\section{REGULACIÓN DE LA RESPONSABILIDAD CIVIL DEL NIÑO QUE TIENE DISCERNIMIENTO}

Observamos que en cuanto a la responsabilidad civil extracontractual prevista en la Sección Sexta del Libro VII Fuente de las obligaciones, no encontramos una norma jurídica que expresamente atribuya responsabilidad civil a un niño o adolescente con discernimiento; los artículos $1975^{\circ}$ y $1976^{\circ}$, que de alguna manera preveían esta situación jurídica fueron derogados por la Única Disposición Complementaria del Decreto Legislativo № 1384 . Aunque, es de advertir que la responsabilidad civil del menor de edad la encontramos más bien en el artículo $458^{\circ}$ del Código Civil, correspondiente al Libro de III Derecho de Familia, que dice: "El menor capaz de discernimiento responde por los daños y perjuicios que cause". 


\section{RESPECTO DE LA CAPACIDAD DE DISCERNIMIENTO DEL NIÑO Y ADOLESCENTE:}

Conforme al citado artículo $458^{\circ}$ del Código Civil todo menor con capacidad de discernimiento es responsable por los daños y perjuicios que cause. Sin embargo, cabe preguntarse ¿A qué edad exactamente el niño adquiere discernimiento? No existe una edad específica que determine con exactitud cuándo un niño ha adquirido el discernimiento o un discernimiento completo. Ni el Código Civil ni el Código de los Niños y Adolescentes lo establece.

Si bien el artículo $43^{\circ}$ de nuestro Código Civil establece que son absolutamente incapaces los menores de dieciséis años, y artículo $44^{\circ}$ en su inciso 1, nos indica que tienen capacidad de ejercicio restringida los mayores de dieciséis y menores de dieciocho, sin embargo, el único presupuesto para determinar si un menor es o no responsable civilmente es el discernimiento, no su edad. En efecto, es la capacidad de entender, comprender y de querer (el discernimiento), el presupuesto único para atribuir responsabilidad al menor. Si bien es relativamente verdad que los niños van adquiriendo discernimiento y madurez a medida que van adquiriendo más edad, sin embargo, hay que tener mucho cuidado en ellos. Bien señala Herrera (2019) que "la capacidad de los niños se desenvuelve hoy bajo la idea de progresividad y se mide para la mayor parte de los actos, en función de la edad, la madurez y el discernimiento suficiente" (p. 1). En este sentido subraya De Trazegnies (1988) que: "no es la capacidad sino el discernimiento lo que determina su responsabilidad o irresponsabilidad, el menor será responsable, cualquiera que sea su edad, si tiene discernimiento" (p. 404); en efecto, con el mismo tenor afirma Leysser León (2017): "la capacidad de discernimiento es, entonces, presupuesto de la responsabilidad civil o, si se prefiere presupuesto de imputación de los efectos resarcitorios previstos por el ordenamiento a cargo del agente" (p. 600).

Es verdad que la edad no es un parámetro necesario para evaluar el desarrollo psíquico e intelectual del menor, la edad puede constituir solo una referencia y como señala Herrera (2019) "debe complementarse necesariamente con la valoración de sus condiciones de madurez y su aptitud suficiente para determinar su capacidad para ejercer cada acto" (p. 2). El criterio de madurez nos remite a las nociones de "evolución de las facultades" y "autonomía progresiva", que son conceptos incorporados por la Convención de los Derechos del Niño. 
¿Qué significa que un niño tenga discernimiento? Significa que el niño o adolescente (menor de 18 años) puede comprender, razonar y entender plenamente las consecuencias de sus actos; es decir que el niño comprende, razona y evalúa que si realiza tal acto generará una consecuencia; o si se quiere, que el niño sabe distinguir qué acto puede producir un daño y que acto no; en efecto, un niño con discernimiento entiende y comprende qué está bien y qué está mal. Al respecto Espinoza (2012) señala que "discernir jurídicamente significa: diferenciar entre hacer o no hacer algo y conocer si ese algo es bueno o malo" (p. 907).

En consecuencia, un niño que no tenga discernimiento no puede atribuírsele una responsabilidad extracontractual por el hecho dañoso que hubiese cometido, porque evidentemente no alcanza a comprender la forma y el resultado de su accionar. Los menores que no tengan discernimiento no se les puede considerar como imputables, ello por cuanto, a criterio de López (2001): "no saben qué consecuencias pueden derivar de su actuación u omisión, y siendo la imputabilidad un elemento de culpabilidad, deben ser calificados como sujetos irresponsables" (p.195); así precisa Espinoza (2003): "el privado de discernimiento, al no ser civilmente imputable, no podrá ser considerando responsable ni subjetiva ni objetivamente" (p. 756).

\section{LA EDAD EN EL DISCERNIMIENTO EN OTROS PAÍSES}

Muchos códigos civiles y normas no se arriesgan a establecer una edad específica que determine el inicio del discernimiento de un niño, por obvias razones, toda vez que el desarrollo cognoscitivo e intelectual de cada niño es distinto y depende de muchos factores sociales, económicos y el mundo en donde se desarrolla.

No obstante, en Alemania, por ejemplo, el Código Civil alemán en su artículo $828^{\circ}$ establece que: "Quien no ha cumplido los siete años de edad, no es responsable de un daño que causa a otro". Aquí, en este párrafo observamos que se aplica un criterio solo biológico, la edad, para determinar que es absolutamente irresponsable. Sin embargo, en el apartado 2 del mismo artículo se indica: "Quién ha cumplido los siete años de edad, pero no los diez no es responsable del daño causado a otro por un accidente de automóvil, ferrocarril o funicular. Ello no rige si la lesión se ha producido dolorosamente"; en efecto, se observa que "aquí emplea un criterio mixto al hacer referencia 'si la lesión se ha producido dolorosamente', por entender que existe mala intención o maldad o una maquinación, lo cual implica discernimiento y por tanto responsabilidad" 
(Plaza, 2016, pág. 68). El párrafo 3 del mismo artículo dice: “Quien todavía no ha cumplido los dieciocho años de edad no es responsable por los daños que causa a otro, en tanto su responsabilidad no resulta excluida según el apartado 1 o 2, si en la realización del acto causante del daño no poseía el necesario discernimiento para comprender la responsabilidad".

Observamos que el Código Civil Alemán indica tres rangos de edad: el primero hasta los siete años totalmente inimputable; el segundo, desde los siete años a diez inimputable para accidentes con automóviles, ferrocarril y funicular; $y$, el tercero que comprende de los siete a los dieciocho años inimputable si no tiene el suficiente discernimiento, de lo que se deduce, en sentido contrario, si se da el discernimiento o si resulta ya como imputable.

Esta misma edad es considerada en el Código Civil portugués, que en su artículo $488^{\circ}$ considera al menor de siete años como inimputable.

En el antiguo Código de Vélez, dice Sconda (2017), se establecía en el artículo $921^{\circ}$ "que los actos ilícitos practicados por menores de diez años eran hechos sin discernimiento" (p. 467). Actualmente el Código Civil y Comercial de Argentina en su artículo $261^{\circ}$ establece que los menores de diez años son incapaces e inimputables, por tanto, no se les puede atribuir directamente ninguna responsabilidad civil; lo que significa que aquí sí el Código establece una edad mínima de capacidad de discernimiento.

\section{ATRIBUCIÓN DE RESPONSABILIDAD CIVIL AL NIÑO QUE AC- TÚA CON DISCERNIMIENTO}

Al no existir en nuestra normatividad civil una edad específica que determine que el niño adquiere el discernimiento o que resulta imputable civilmente, corresponderá al Juez examinar caso por caso, y según las circunstancias, si actuó o no con discernimiento; en este sentido se indica que: "el único método válido de establecer el discernimiento consiste en examinar al niño causante del daño y determinar si ese niño en particular tiene un grado de desarrollo físico e intelectual que le permita discernir los efectos dañinos de su actos" (De Trazegnies, 1988, p. 404).

En efecto, aquel niño (menor de dieciocho años) que actuando con discernimiento ocasiona un daño a un tercero, debe asumir su responsabilidad resarciendo el daño a la víctima, aplicándose en este caso lo dispuesto por el artículo 1969 del Código Civil el cual establece que: “Aquél que por dolo 
o culpa causa un daño a otro está obligado a indemnizarlo. El descargo por falta de dolo o culpa corresponde a su autor". No existe justificación en este caso para no atribuir responsabilidad civil extracontractual a un menor que actúa con discernimiento; en consecuencia, se encuentra obligado a resarcir el daño ocasionado.

Cabe precisar, que no sería muy difícil para un juez determinar si el niño actúo con discernimiento en el hecho dañoso si por ejemplo este menor de edad es un adolescente que ha constituido una persona jurídica de carácter asociativo sin fines de lucro (artículo $13^{\circ}$ del CNA) o que trabaja con autorización de sus representantes conforme lo prevé al artículo $51^{\circ}$ del CNA (por ejemplo un menor de 12 años de edad excepcionalmente) o cuando ha cesado su incapacidad conforme a lo previsto en el artículo $46^{\circ}$ del Código Civil.

\section{VI. ¿QUIÉN RESPONDE CIVILMENTE POR EL DAÑO OCASIONA- DO POR EL NIÑO Y/O ADOLESCENTE?}

Se presentan tres situaciones distintas en este caso. En el primer supuesto: cuando el niño actuó con discernimiento en el hecho que produjo el daño a un tercero, pero que no tiene patrimonio con qué resarcir el daño ¿Quién debe responder en este caso? El segundo supuesto: cuando el niño actuó sin discernimiento, pero es inimputable para ser responsabilizado por el hecho ¿Quién debe resarcir el daño ocasionado a la víctima? Pues, el hecho que haya actuado sin discernimiento, no significa que la víctima del daño quede sin resarcimiento; y el tercer supuesto: cuando el niño actúa con o sin descernimiento, pero al momento del hecho se encontraba bajo la vigilancia y cuidado de una institución educativa, lejos del cuidado de los padres o del representante legal ¿Quién debe responder por el daño en este caso?

\section{Primer supuesto: reparación del daño ocasionado por el niño que actuó con discernimiento}

Sabemos que si el menor actúa con discernimiento es civilmente responsable por el daño que cause y se encuentra obligado resarcir el daño. Cuando este menor causante del daño tiene bienes patrimoniales o ingreso económicos no existe inconveniente para que pueda responder con sus propios bienes por el daño ocasionado a la víctima. Sin embargo, en la mayor parte de los casos, casi siempre, el problema surge cuando el niño no tiene con qué responder ¿quién responde por el daño causado a la víctima? La respuesta 
precisa la tenía el artículo $1975^{\circ}$ de nuestro Código Civil que establecía: “La persona sujeta a incapacidad de ejercicio queda obligada por el daño que ocasione, siempre que haya actuado con discernimiento. El representante legal de la persona incapacitada es solidariamente responsable". De esta norma, injustificadamente derogada, podía advertirse de su segundo párrafo, que el representante legal, que para el caso de los niños serían sus padres, respondían en forma solidaria. Resultaba claro que los padres debían responder por el daño ocasionado por sus hijos menores (incapacitados). De esta disposición normativa se deducía claramente que el niño (sujeto a incapacidad de ejercicio) que actuaba con discernimiento quedaba obligado por el daño que cause a un tercero; es decir, el niño debía responder con sus bienes para resarcir el daño; y no solo el niño, la víctima podía exigir resarcimiento indistintamente a los padres del menor (representante legal) quien se obligada solidariamente, por mandato expreso de la ley.

Sin embargo, el citado artículo $1975^{\circ}$ ha sido derogado desafortunadamente (por el Decreto Ley $N^{\circ} 1384$, del 04/09/018) sin mayor fundamento ni sustento, dejando un vacío normativo, puesto que ya no hay disposición expresa en nuestro código civil que regule un supuesto de hecho similar. Si bien el artículo $458^{\circ}$ del Código Civil establece que el menor capaz de discernimiento responde por el daño que cause, sin embargo, omite señalar si los padres o representantes legales del menor responden o no solidariamente.

\section{Segundo supuesto: reparación del daño ocasionado cuando el niño actuó sin discernimiento}

Si el menor incapaz de discernimiento ocasiona un daño a otro, el menor resulta inimputable al no tener la capacidad de comprender y querer el hecho realizado; por tanto, no se le puede atribuir ninguna responsabilidad. No obstante, existe un daño injusto y una víctima que tiene que ser resarcida, la víctima tiene derecho a ser resarcida o compensada por el daño sufrido ¿Quién debe responder por este daño? En nuestro Código Civil dicho supuesto también estaba regulado en el artículo $1976^{\circ}$ (actualmente derogado) y decía lo siguiente: "No hay responsabilidad por el daño ocasionado por persona incapaz que haya actuado sin discernimiento, en cuyo caso responde el representante legal". Las víctimas del daño encontraban aquí un fundamento legal expreso para exigir resarcimiento al representante legal (padres) del menor causante del daño culposo. Sin embargo, al haber sido desafortunadamente derogado el citado artículo $1976^{\circ}$ (por el Decreto Ley $\mathrm{N}^{\circ} 1384$ del 04/09/018) ha quedado un vacío normativo y las víctimas con desamparo legal. 
De Trazegnies (1988) cuando analizaba los artículos $1975^{\circ}$ y $1976^{\circ}$, antes de su derogación, decía: "cuando se trata del daño cometido por un incapaz de cualquier tipo, el representante siempre es responsable, ya sea que el incapaz haya actuado con discernimiento o sin discernimiento" (p. 409).

\section{Tercer supuesto: reparación del daño causado cuando el niño actúa con o sin descernimiento, pero dentro de una institución educativa}

Un tercer supuesto es cuando el niño no se encuentra bajo custodia y vigilancia de sus padres, sino que se encuentra lejos de la tutela y custodia de los padres, encontrándose en una institución previamente convenida con esta. Si partimos de la teoría subjetivista que establece que la responsabilidad de los padres por los daños que ocasionen sus hijos se origina en la falta de vigilancia y cuidado hacia los hijos, los padres no serían responsables cuando los menores se encuentren bajo la vigilancia, cuidado y autoridad de terceras personas; en este caso, responden las personas que lo tienen bajo cuidado y vigilancia o las personas que ejercen autoridad sobre el menor de manera momentánea. Por ejemplo, cuando el niño se encuentra en una institución educativa, los encargados de vigilancia y cuidado se trasladan a las autoridades de la institución educativa, quienes no solo tienen la obligación de dar la enseñanza educativa correspondiente, sino que se hace responsable también de la seguridad y protección del niño. Esta responsabilidad de protección viene impuesta por la Constitución Política del Estado que en su artículo $4^{\circ}$ establece que es una obligación fundamental de la comunidad y el Estado la protección especialmente al niño y al adolescente, pero no solo nuestra Constitución, sino la Convención sobre los Derechos del Niño que en su artículo $3^{\circ}$ numeral 2, señala que los Estados Partes se comprometen a asegurar al niño la protección y el cuidado que sean necesarios para su bienestar. Sin embargo, hay que distinguir dos casos, uno cuando el daño es ocasionado por el menor que actuó con discernimiento, en este caso será la institución educativa quien responda solidariamente, y si el menor actuó sin discernimiento la responsabilidad será total de la institución educativa. Es decir que la víctima del daño puede demandar resarcimiento por responsabilidad civil indistintamente a la institución educativa o al menor que actuó con discernimiento o solamente puede demandar a la institución educativa si el menor actuó sin discernimiento, en este último caso se justifica porque tratándose de un niño sin discernimiento los cuidados y vigilancia que debe desplegar la institución educativa es mucho mayor y su responsabilidad es mayor también. En este sentido se indica que: "La cuestión es delicada porque en ella se ven inmersas personas que aún no tienen plena capacidad, por falta de edad y de madurez, para discernir lo que 
objetivamente puede estar bien o mal, lo que puede ser generador de riesgos o lo que puede causar un resultado dañoso para ellos mismos o para otra persona. De ahí la necesidad de ese deber de vigilancia, control y cuidado de los centros educativos" (Muñoz, 2009, p. 1). Si bien uno de los deberes que asume la institución educativa, ante los niños matriculados en su institución, es enseñar, sin embargo, junto a este importante deber, existe otro de la misma importancia y categoría, cual es el deber de vigilancia y protección del niño mientras esté bajo su autoridad; así Guido Alpa (2006) indica que: "El deber de educación está en correlación con el deber de vigilancia" (p. 849).

Precisando la responsabilidad del titular de centro educativo Atienza (2014) refiere que: "La culpa consistirá, como vimos, en no haber adoptado las medidas de organización o de seguridad necesarias para el funcionamiento del servicio de la educación; o bien, culpa in vigilando o in eligendo, en relación con la actuación negligente de los encargados de vigilar y controlar a los alumnos" (p. 415).

\section{RESPONSABILIDAD CIVIL DE LOS PADRES POR LOS DAÑOS OCASIONADOS POR SUS HIJOS QUE HABITEN CON ELLOS}

Existe la obligación de reparar un daño causado a otros, sea por culpa o negligencia, así nos lo indica el Código Civil artículo 1969. Sin embargo, esta obligación no solo supone responder de los actos propios, sino también de los de aquellas personas de las que debemos responder, como los hijos que están bajo nuestra guarda y responsabilidad.

No existe discusión en la doctrina acerca de que los padres o los representantes legales de los menores (con o sin discernimiento) responden por los daños que pudieran ocasionar sus hijos que habiten con ellos. Sí genera controversia, en cambio, si esta responsabilidad se fundamenta en la culpa de los padres (por falta de vigilancia y cuidado del menor) o se trata de una responsabilidad objetiva que prescinde de dicha culpabilidad. En este sentido señala Plovanich (2015) que: "cuando en la producción del daño interviene un menor resulta dificultoso para los magistrados calificar sin más como negligentes las conductas de los padres, a la vez que son conscientes de que alguien ha sufrido un daño que generalmente no tiene por qué soportar" (p.1).

Las razones que permiten asignarle responsabilidad civil a los padres del menor por el hecho dañoso de sus hijos menores han transitado desde una responsabilidad subjetiva a una responsabilidad objetiva a través de la jurisprudencia. 


\subsection{Sustento en la responsabilidad subjetiva:}

En sus orígenes la responsabilidad de los padres por los hechos de sus hijos menores fue subjetiva, sustentado en la culpa de los padres; fue el mismo Pothier quien formuló un principio general en virtud del cual el padre deberá responder salvo que, hubiera probado que no pudo impedir el hecho del menor; si bien partía de la presunción de culpa, sin embargo, existía la posibilidad de liberarse de dicha responsabilidad si probaran que no pudieron evitar el acto dañoso.

Es decir que originariamente este tipo de responsabilidad se atribuía a los padres porque con su actuación u omisión habían permitido que su hijo menor cometiese el hecho dañoso que perjudicó a otro, se trataba entonces de una coautoría. Esta responsabilidad directa al padre se sustentaba en la culpa por no haber vigilado o cuidado adecuadamente al menor y si bien era una culpa presunta, aún tenía el padre la posibilidad de liberarse de esta responsabilidad si demostraba que había hecho todo lo posible para impedir el acto dañoso del menor y que, no obstante, no pudo impedir el hecho. No se atribuía la responsabilidad a los padres por el solo hecho de ser padres, sino por su culpabilidad por la falta de vigilancia ante el hijo menor que cometió el hecho dañoso. En este sentido Luigi Corsaro expresa que: "que, en la senda trazada por Pothier, hubo de afirmarse, no por la posición paternal de la persona, sino solo y en cuanto el padre no hubiera impedido el hecho que habría podido impedir, concretamente" (p. 64).

En efecto, el fundamento para atribuir responsabilidad a los padres era la culpa, la culpa del padre por la falta de vigilancia y cuidado hacia el menor; así López (2001) indica que: "la responsabilidad no nace porque las personas de las que se debe responder hayan cometido un ilícito, sino porque ellos mismos, debido a una negligencia que se presume, no han podido evitar que se produjera" (p. 202). En esta teoría se parte de del principio de que los padres ejercen autoridad sobre sus hijos y como tal se encuentran obligados a vigilar y cuidar de sus hijos menores mientras vivan o habiten con ellos o se encuentren bajo su cuidado, por ende, eran responsables por esa falta de vigilancia y cuidado hacia el menor; así se indica que: "el fundamento originario de la responsabilidad de los padres por los hechos dañosos que hubieren causado sus hijos menores, residía en la autoridad que ejercen sobre estos, teniendo en cuenta que dicha autoridad incluía la obligación de vigilarles y educarles correctamente" (López, 2001, pág. 98); por ello, también señala Gallego (2011) que: "solo debería surgir responsabilidad cuando verdaderamente se ha infringido esta obligación de vigilancia, de cuidado, no cuando el daño se ha producido con independencia de la 
actuación de los padres e incluso a pesar del cuidado desplegado" (p. 474); en el mismo sentido indica Tovani (2012): "la causa del evento no solo es el comportamiento del niño, sino también la falta de supervisión o de la educación por los padres, que es concausa" (p. 261); la responsabilidad de los padres por el hecho de sus hijos menores se fundamenta, según Estrada (2012), "en la presunción de cupa por falta o mala vigilancia o en la culpa probada por falta o mal educación, de quien tiene bajo su cuidado al menor" (p. 58).

Puede asimismo verse que los Códigos Civiles europeos, el francés, el italiano y el español, al regular la responsabilidad civil de los padres por los hechos de sus hijos lo hicieron desde el ámbito subjetivo; $y$, si bien presumían una culpa presunta de los padres, sin embargo, otorgaban la posibilidad a los padres de exonerarse de su responsabilidad si probasen que desplegaron toda su diligencia para impedir el hecho.

Así, por ejemplo, el Código Civil Francés en su artículo $1384^{\circ}$ en su redacción originaria establece que: "En la medida en que ejerzan la patria potestad, el padre y la madre se responsabilizarán solidariamente del daño causado por sus hijos menores que habiten con ellos. ... Los maestros y los artesanos, del daño causado por sus alumnos y aprendices mientras estuviesen bajo su supervisión. La responsabilidad mencionada anteriormente se contraerá a menos que los progenitores y los artesanos demuestren que no pudieron impedir el hecho que diese lugar a dicha responsabilidad. ...". Se ve claramente de esta norma que los progenitores (padre y madre) tienen la oportunidad de demostrar ante el juez de que no pudieron impedir el hecho que originó el daño, en cuyo caso quedaban exonerados de responsabilidad. Lo que significa que la responsabilidad era subjetiva.

Por su parte, el Código Civil Italiano de 1942 en su artículo $2047^{\circ}$ establece lo siguiente: "En caso de un daño ocasionado por una persona incapaz de discernimiento o de voluntad, el resarcimiento correrá a cargo de quien estaba obligado a la vigilancia del incapaz, salvo que demostrara no haber podido impedir el hecho. ..."; y en el artículo $2048^{\circ}$ indica lo siguiente: "El padre y la madre, o el tutor, son responsables del daño ocasionado por el hecho ilícito de los menores no emancipados, o de las personas sujetas a tutela que habiten con ellos. ... Las personas indicadas en los párrafos precedentes quedan libres de responsabilidad solamente cuando probaren no haber podido impedir el hecho".

Se observa que el artículo $2047^{\circ}$ está referido a una persona incapaz de discernimiento, que bien puede ser el niño que aún no ha adquirido esa capacidad de discernir, en cuyo caso responde el que estaba obligado a la 
vigilancia, que normalmente corresponde a los padres vigilar a los hijos incapaces de discernimiento; no obstante, hay que precisar aquí, también puede ocurrir que la vigilancia esté a cargo de una institución educativa, como por ejemplo, cuando el menor ingresa al centro educativo a recibir sus estudios, aquí escapa de la vigilancia de los padres, recayendo la responsabilidad en caso de daño la institución educativa.

Por su parte, en el artículo $2048^{\circ}$ está referido para un menor con capacidad de discernimiento, en este caso los padres pueden quedar libres de responsabilidad si probasen que no pudieron impedir el hecho del menor a pesar de los cuidados desplegados; en sentido Leysser León (2017) afirma que: "la técnica legislativa utilizada por el legislador italiano es la presunción de responsabilidad: el que tiene a su cuidado al incapaz responde a menor que pruebe que no pudo impedir el hecho" (p. 602).

Conforme puede observarse de la regulación de los citados artículos $2047^{\circ}$ y $2048^{\circ}$ se atribuye a los padres una responsabilidad presunta por falta de vigilancia hacia los hijos; en este contexto Alpa (2006) cita una casación italiana del 30/10/1984, en la que indica que "la responsabilidad ex artículo $2048^{\circ}$ es una responsabilidad directa y no una responsabilidad indirecta, objetiva o por hecho ajeno, que implica una culpa específica y presunta consistente en a negligencia, en la educación impartida o en la vigilancia" (pág. 2016).

A su turno el Código Civil español en su artículo $1903^{\circ}$ establece lo siguiente: "Los padres son responsables de los daños causados por los hijos que se encuentren bajo su guarda. .... La responsabilidad de que trata este artículo cesará cuando las personas en él mencionadas prueben que emplearon toda la diligencia de un buen padre de familia para prevenir el daño".

Observamos que esta disposición otorga la posibilidad a los padres de exonerarse de la responsabilidad por el daño de sus hijos si prueban que emplearon toda la diligencia para prevenir el hecho.

Por ejemplo, el Tribunal Supremo español, en una sentencia del 22/09/1984, estableció que: "la responsabilidad civil de los padres que dimana de los actos realizados por hijos que se encuentran bajo su potestad, se justifica por la transgresión del deber de vigilancia que les incumbe, estableciendo el legislador una presunción de culpa en quien desempeña la patria potestad, e insertando un matiz objetivo en la responsabilidad" (Nevado, 2018, p. 2). 
Puede concluirse que en estos tres códigos civiles mencionados se observa que se responsabiliza a los padres del menor por no haber empleado toda la diligencia para impedir y prevenir el hecho.

\subsection{Sustento de la responsabilidad objetiva de los padres}

Sostiene Sconda (2017) que "en el derecho moderno la responsabilidad parental tiene a fundarse no en el deber de vigilancia, en la culpa in vigilando, sino en la relación de paternidad y la necesidad de no dejar desamparada a la víctima de un hecho ilícito" (p. 473).

En la tesis objetiva el padre responde solo por el hecho de ser el padre, es decir por la relación de familiaridad y como indica Alpa (2006), "sin una efectiva o sustancial participación en la creación del daño" (p. 844); lo que significa se prescinde de la culpa. Los padres asumen responsabilidad por sus hijos menores y se hacen cargo de cualquier daño que los menores pudieran producir, ello con la finalidad de garantizar el resarcimiento del daño a la víctima que es uno de los fines de la responsabilidad civil.

El cambio de sentido de una responsabilidad subjetiva a una responsabilidad objetiva de los padres por los hijos se sustenta en muchas razones válidas, entre ellas tenemos un cambio de paradigma en la relación de los padres hacia los hijos, la mayor independencia y voluntad de actuación de los menores y la garantía del resarcimiento de la víctima, lo que hace que el menor actúe con mayor libertad y autonomía en el ejercicio de sus derechos relegando la participación y autoridad de los padres, en este contexto es muy difícil atribuir a los padres una responsabilidad por falta de vigilancia y cuidado.

Si bien antes se sostenía jurídicamente que los padres podían ejercer un control irrestricto hacia sus hijos menores corrigiendo moderadamente sus conductas, ahora ello ya no es posible; los padres se encuentran limitados por el reconocimiento de los derechos de los niños y adolescentes quienes ejercen ahora sus derechos con mayor libertad y autonomía que antes y existe hacia ellos una protección integral; siendo que la actuación de los padres es más bien de respeto mutuo, velar por su desarrollo integral, proveer su sostenimiento y educación, dirigir su proceso educativo y tenerlos en su compañía (así lo regula expresamente el artículo $74^{\circ}$ del CNA); al menor ya no se le puede "corregir moderadamente", se ha eliminado el tradicional derecho de corrección. Bajo esta perspectiva con acierto se señala que: "En 
la actualidad las relaciones entre padres e hijos han cambiado, y el nivel de control, por lo general, se ha reducido por las circunstancias educativas y socioeconómicas, existiendo un grado de vigilancia menor al que existía históricamente, y diferente al que tuvieron en mente los legisladores de 1889, cuando la mayoría de edad se alcanzaba más tarde" (Nevado, 2018, p. 3).

Es una verdad evidente que estamos ante una nueva doctrina, la doctrina de la protección integral del niño como sujetos de plenos derechos, cuyo respeto se debe garantizar; al respecto señala Gallegos (2011) que: "La vida en la actualidad ha cambiado mucho y sería absurdo no reflexionar siquiera un momento sobre la autonomía y libertad de la que hoy día en día gozan los menores y pupilos" (p. 481). Siendo que los niños y adolescentes gozan ahora de un mayor grado de libertad y autonomía en el ejercicio de sus derechos no podría responsabilizarse a los padres por una falta de vigilancia y cuidado, puesto que sería imposible ejercer un control de vigilancia permanentemente.

Otro aspecto que ha obligado a la jurisprudencia a cambiar del factor de atribución subjetivo a uno objetivo es el hecho que bajo la mirada de la culpa los resarcimientos por el daño ocasionado se hacían casi imposibles, ello por cuanto se llegaba a determinar que los padres no podían estar siempre presente en cada momento durante el día junto al menor, puesto que los menores no podían ser objeto de control durante todo el tiempo; así, señala Gallegos (2011) que los menores: "son seres vivos con un grado de autonomía y libertad que no pueden ser objeto de control total y absoluto por parte de los padres" (p. 474), por eso no se podía concluir que si se produce un daño es porque necesariamente ha habido una falta de control total o vigilancia del padre.

Se sostiene que: "La tendencia moderna se orienta a responsabilizar objetivamente a los representantes legales, en razón de que la aplicación rigurosa de la culpa in vigilando privaría a muchas víctimas de reparación: la mayor parte de los representantes legales no estaría incurso en la culpa" (De Trazegnies, 1988, p. 414). Algunos señalan que existen dos razones que llevan al cambio de esta tendencia a la objetivación de la responsabilidad de los padres: la primera: "los hijos menores de edad tienen hoy mucha más libertad de actuación que en épocas anteriores. Si entonces se entiende que el incremento de autonomía del menor conlleva mayor responsabilidad, no resulta fácil calificar sin más de negligentes las conductas de sus padres" (Durany, 2000, p. 2), el mismo autor agrega como segunda razón que aunque 
los padres pudieran haberse comportado correctamente, lo cierto es que alguien ha sufrido un daño que, por lo general, no tiene por qué soportar.

Si bien los códigos civiles europeos no han modificado sus disposiciones referidas a la responsabilidad por culpa de los padres por los actos dañosos de sus hijos, sin embargo, la jurisprudencia ha venido exigiendo rigurosamente la prueba de la buena diligencia (de que se había actuado con la diligencia para evitar el daño), lo que en la práctica resulta casi imposible liberarse de esta responsabilidad. Así lo señala Durany (2000) comentarista español indicando que: "Antes, los tribunales responsabilizaban a los padres por los daños de sus hijos si la vigilancia paterna había sido insuficiente: aplicaban el criterio de culpa invigilando. Hoy los hacen responsables por el simple hecho de ser padre" (p. 1); se destaca además que: "la jurisprudencia en no pocas ocasiones entiende que la falta de cuidado del padre o de la vigilancia del menor crea el riesgo de una conducta nociva, estableciéndose un enlace con la responsabilidad de los padres, en cuanto creadores del riesgo derivado en ocasiones a una responsabilidad cuasi objetiva, primando la garantía del cobro del perjudicado" (Ramón, 2012, pág. 4). Incluso una sentencia del Tribunal Supremo español (Sala de lo Civil, nº 226/2006, de 08/03/2006, Rec. 2586/1999) señala lo siguiente: "la responsabilidad declarada en el Art. 1903 ,Código Civil, aunque sigue a un precepto que se basa en la responsabilidad por culpa o negligencia, no menciona tal dato de culpabilidad y por ello se ha sostenido que contempla una responsabilidad por riesgo o cuasi objetiva, justificándose por la trasgresión del deber de vigilancia que a los padres incumbe sobre los hijos sometidos a su potestad con presunción de culpa en quien la ostenta y la inserción de ese matiz objetivo en dicha responsabilidad, que pasa a obedecer a criterios de riesgo en no menor proporción que los subjetivos de culpabilidad, sin que sea permitido ampararse en que la conducta del menor, debido a su escasa edad y falta de madurez, no puede calificarse de culposa, pues la responsabilidad dimana de culpa propia del guardador por omisión del deber de vigilancia".

En Latinoamérica, observamos que el Código Civil chileno también regula una responsabilidad subjetiva, aunque con culpa presunta; así en el artículo $2320^{\circ}$ dice: "Toda persona es responsable no solo de sus propias acciones, sino del hecho de aquellos que estuvieren a su cuidado. Así el padre, y a falta de este la madre, es responsable del hecho de los hijos menores que habiten en la misma casa. (...) Pero cesará la obligación de esas personas si con la autoridad y el cuidado que su respectiva calidad les confiere y prescribe, no hubieren podido impedir el hecho". También cabe 
destacar aquí el artículo $2319^{\circ}$ del mismo Código que indica: "no son capaces de delito o cuasidelito los menores de siete años ...; pero serán responsables de los daños causados por ellos las personas a cuyo cargo estén, si pudiere imputárseles negligencia".

De otro lado, el Código Civil y Comercial de Argentina en cambio sí ha regulado recientemente y de modo textual la responsabilidad solidaria y objetiva de los padres por los daños que ocasionen los menores que viven con ellos; así esta responsabilidad se encuentra regulada en los siguientes artículos: artículo $1754^{\circ}$ "Los padres son solidariamente responsables por los daños causados por los hijos que se encuentren bajo la responsabilidad parental y concurrente que pueda caber a los hijos" y artículo $1755^{\circ}$ "La responsabilidad de los padres es objetiva, y cesa si el hijo menor de edad es puesto bajo la vigilancia de otras personas, transitoria o permanentemente. Los padres no se liberan, aunque el hijo menor de edad no conviva con ellos, si esta circunstancia deriva de una causa que no es atribuible". Observamos que el Código Civil argentino ha optado por la objetividad de la responsabilidad de los padres, es decir que en todos los casos en que está bajo su vigilancia serían responsables, no podrían recurrir a la fórmula de que "hicieron todo lo posible para prevenir o evitar el hecho, pero no pudieron", esto ya no es justificación, la culpabilidad por falta de vigilancia o cuidado es irrelevante, ella se deja totalmente de lado. Los padres ahora asumen su responsabilidad por la simple relación paterno filial, es decir por el solo hecho de ser padres y estar al cuidado de sus hijos.

\section{CON REFERENCIA A NUESTRO CÓDIGO CIVIL DE 1984}

Decíamos que nuestro Código Civil inicialmente regulaba una responsabilidad civil de los representantes legales por el hecho de las personas incapaces con o sin discernimiento; bajo este supuesto los padres respondían siempre por los hechos de sus hijos menores que actuaron con o sin discernimiento, y esta responsabilidad era prácticamente objetiva, pues los padres como representantes legales del hijo menor de edad, respondían de todos modos, sin justificación alguna. Así, el artículo 1975, antes de su derogatoria, establecía: "La persona sujeta a incapacidad de ejercicio queda obligada por el daño que ocasione, siempre que haya actuado con discernimiento. El representante legal de la persona incapacitada es solidariamente responsable". De aquí podía deducirse que el menor de edad, niño o adolescente, con discernimiento quedaba obligada por el daño que pudiera ocasionar ¿Quién respondía en este 
caso? No solo el menor sino también el padre como su representante legal en forma solidaria. En efecto, si el menor no tenía bienes patrimoniales con qué responder, eran los padres quienes debían hacerse cargo de la responsabilidad. Asimismo, el artículo $1976^{\circ}$, antes de su derogatoria, disponía: "No hay responsabilidad por el daño ocasionado por persona incapaz que haya actuado sin discernimiento, en cuyo caso responde el representante legal". De esta disposición se deducía que el menor sin capacidad de discernimiento no tenía responsabilidad alguna, en cuyo caso, a efectos de no dejar sin resarcimiento a la víctima, debían responder los padres. Este último artículo era complementado con el artículo $1977^{\circ}$ que curiosamente sí se dejó vigente, el cual establece que: "Si la víctima no ha podido obtener reparación en el supuesto anterior, puede el Juez, en vista de la situación económica de las partes, considerar una indemnización equitativa a cargo del autor del hecho". Esta disposición solo era aplicable cuando en el supuesto del artículo $1976^{\circ}$ el representante legal no tenía medios económicos para responder por el daño causado por el privado de discernimiento, en cuyo caso, debía recurrirse al patrimonio de la persona causante del daño (privado de discernimiento) para otorgar una indemnización, ello con la finalidad de no dejar desamparada a la víctima, pues el daño tenía que ser de alguna manera reparado. En este sentido afirmaba Espinoza: "la indemnización a favor de la víctima, se hará a cargo del patrimonio del autor directo, o sea el incapaz sin discernimiento, no por el hecho de que este sea responsable, sino que, en base a la equidad, se quiere evitar que la víctima, ante la insuficiente de recursos económicos del representante legal, asuma los costos de los daños ocasionados" (Espinoza, 2015, p. 150). Pues, si bien no se puede atribuir responsabilidad civil a un privado de discernimiento, sin embargo, observando que este tiene bienes patrimoniales que muy bien pueden compensar el daño ocasionado, el juez puede en este caso otorgar "una indemnización equitativa", es decir no un resarcimiento completo del daño como debería ser en el caso del daño ocasionado, sino una indemnización que de alguna manera subsane o ayude en la reparación del daño ocasionado, ello queda a discreción del juez teniendo como parámetro la situación económica de las partes.

\section{CONCLUSIONES}

1.- Los niños y adolescentes con discernimiento son responsables extracontractualmente cuando ocasionan un daño a un tercero; por tanto, se encuentran obligados a resarcir el daño que hubieren 
ocasionadoen talcondición. Los menores incapaces de discernimiento no pueden ser responsables civilmente por no ser imputables, pues aún no tienen la capacidad de comprender y querer.

2.- En ambos casos (niños y adolescentes que actúan con o sin discernimiento) los padres responden por el daño ocasionado por sus hijos, sea directamente o solidariamente; esta responsabilidad puede originarse como consecuencia de una falta de vigilancia y cuidado hacia los hijos, lo que sería una responsabilidad subjetiva y directa; o también puede responder por el solo hecho de ser, es decir bajo una responsabilidad objetiva con prescindencia de culpa.

3.- No es la edad lo que debe tomarse en cuenta para atribuir o no responsabilidad civil a un niño o adolescente, sino su capacidad de discernimiento; no existe una edad exacta para determinar si un niño alcanzó o no el discernimiento, corresponderá al juez en cada caso particular determinarlo.

4.- Si bien la responsabilidad de los padres por los hijos menores tiene su origen en una responsabilidad por culpa (falta de vigilancia o cuidado), sin embargo, tanto la doctrina como la jurisprudencia, y algunos códigos civiles más recientes optan por la responsabilidad objetiva prescindiendo de toda culpabilidad, ello con la finalidad de garantizar siempre el resarcimiento a la víctima.

5.-Resulta muy difícil ahora sostener que la responsabilidad de los padres por los hijos menores se sustenta en una responsabilidad por falta de vigilancia y cuidado, por cuanto no es posible que todo el tiempo el padre pueda supervisar la actuación del menor, quien ahora puede ejercer sus derechos con mayor autonomía y libertad que antes.

6.- Los padres solo pueden eximirse de responsabilidad cuando el menor se encuentra bajo la vigilancia y cuidado de la institución educativa en el momento que ocurrieron los hechos causantes del daño.

7.- En nuestro Código Civil lamentablemente ya no existe una disposición normativa que establezca expresamente responsabilidad civil (objetiva o subjetiva) de los padres por los daños injustos de sus hijos menores, resultando necesario que se regule, ello con la 
finalidad de que las víctimas del daño no tengan inconvenientes a la hora de exigir el resarcimiento por el daño sufrido.

\section{REFERENCIAS}

Alpa, G. (2006). Nuevo tratado de la responsabilidad civil. Lima Perú. Juristas editores.

Atienza, L. (2014). La responsabilidad civil por los hechos dañosos de los alumnos menores de edad. (Tesis doctoral). Universidad de Valencia. Recuperado de: https:// dialnet.unirioja.es.

Durany, S. (2000). Padres y maestros. Indret: Revista para el Análisis del Derecho, ISSN-e1698-739X, №1. Recuperado de http://www.indret.com/pdf/007_ es.pdf

Espinoza, J (2003). La influencia de la experiencia jurídica italiana en el Código Civil peruano en materia de responsabilidad civil. Recuperado de: https://dialnet. unirioja.es/descarga/articulo/5084778.pdf.

Espinoza, J. (2012). Derecho de las Personas - Tomo I. Lima: Grijley.

Espinoza, J. (2015). Indemnización equitativa. En Tratado de responsabilidad civil contractual y extracontractual. pp. 149-150.

Estrada, L. (2012). Responsabilidad civil parental por acoso escolar del hijo menor de edad en Colombia. En: revista de la Facultad de Derecho y Ciencias Políticas. Vol. 42, No. 116. Recuperado de http://www.scielo.org.co/pdf/rfdcp/ v42n116/v42n116a09.pdf.

Gallegos, I. (2011). Responsabilidad civil de los padres y tutores por daños causados por menores y personas incapacitadas. Derecho de daños. Motivensa Editores. $469-485$

Herrera, S. (2019). El rol jurídico de los menores en la actualidad. En: microjuris.com. Recuperado de https:/ / aldiaargentina.microjuris.com

León, L. (2017). La responsabilidad civil. Líneas fundamentales y nuevas perspectivas. Tercera edición, instituto pacífico. 
López, C. (2001). La responsabilidad extracontractual del menor. Tesis doctoral. Recuperado de: https//rua.ua.es/dspace/bistream/10045/6710/1

Muñoz, P. (2009). Responsabilidad civil de los titulares de centros docentes. En: Diario La Ley, № 7231, Sección Dossier, 1 de septiembre de 2009, Recuperado de http:/ /guiasjuridicas.wolterskluwer.es

Nevado, J. (2018). La responsabilidad civil de los padres por daños causados por sus hijos menores en supuestos de no convivencia. En Noticias Juridicas.com. Recuperado de http://noticias.juridicas.com/conocimiento/articulosdoctrinales / 12649-la-responsabilidad-civil-de-los-padres-por-danoscausados-por-sus-hijos-menores-en-supuestos-de-no-convivencia /

Plaza, J. (2016). La responsabilidad por los hechos dañosos de los menores (especial consideración de los centros de enseñanza no universitarios). Tesis doctoral. Universidad de Valladolid, España. Recuperado de http:/ / uvadoc.uva.es / handle/10324/16742

Plovanich, M. (2015), Responsabilidad de los padres en el Código Civil y Comercial. Recuperado de https://www.pensamientocivil.com.ar/system/ files/2015/11/Doctrina2252.pdf

Ramón, F. (2012). La responsabilidad civil en el ámbito de los menores. Revista sobre la infancia y los adolescentes. Recuperado de https://doi.org/10.4995/ reinad.2012.1118

Sconda, M. (2017) La responsabilidad de los padres de los hechos ilícitos ocasionados por sus hijos. En: Biblioteca jurídica virtual del Instituto de Investigación Jurídica de la UNAM. Recuperado de https:/ /archivos.juridicas.unam.mx/www / bjv/libros/10/4669/29.pdf

Tovani, F. (2012). Familia y responsabilidad civil: reflexiones sobre la responsabilidad de los padres respecto de sus hijos y respecto de los terceros en Italia. Recuperado de https://dialnet.unirioja.es/descarga/articulo/6119848.pdf

Trazegnies, F. (1988). La responsabilidad extracontractual. Tomo I. Pontifica Universidad Católica del Perú.

Fecha de recepción: 30-09-2020

Fecha de aceptación: 16-11-2020 